\title{
Misuse of prophylactic antibiotics and prevalence of postoperative wound infection in obstetrics and gynecology department in a Sudanese hospital
}

\author{
Abubaker Ibrahim Elbur ${ }^{1^{*}}$, M. A. Yousif ${ }^{2,3}$, Ahmed S. A. El Sayed ${ }^{4}$, Manar E. Abdel-Rahman ${ }^{5}$ \\ ${ }^{1}$ Pharmacy Practice Research Unit (PPRU), College of Pharmacy, Taif University, Taif, KSA; \\ *Corresponding Author: bakarelbu@yahoo.co.uk \\ ${ }^{2}$ Faculty of Pharmacy, Gezira University, Wad Madani, Sudan \\ ${ }^{3}$ Pharmacy Practice Research Unit (PPRU), College of Pharmacy, Taif University, Taif, KSA; mirghani53@yahoo.com \\ ${ }^{4}$ Department of Cardiothoracic Surgery, Al-Shaab Teaching Hospital, Khartoum, Sudan; asaelsayed@hotmail.com \\ ${ }^{5}$ Faculty of Mathematical Sciences, University of Khartoum, Khartoum, Sudan; manarr@hotmail.com
}

Received 14 November 2013; revised 25 December 2013; accepted 6 January 2014

Copyright (C) 2014 Abubaker Ibrahim Elbur et al. This is an open access article distributed under the Creative Commons Attribution License, which permits unrestricted use, distribution, and reproduction in any medium, provided the original work is properly cited. In accordance of the Creative Commons Attribution License all Copyrights (C) 2014 are reserved for SCIRP and the owner of the intellectual property Abubaker Ibrahim Elbur et al. All Copyright @ 2014 are guarded by law and by SCIRP as a guardian.

\section{ABSTRACT}

Purpose: This study was conducted to audit prophylactic antibiotic use and to quantify the rate of wound infection. Methods: Across-sectional prospective study was conducted in the Obstetrics and Gynecology Department in Khartoum Teaching Hospital, Sudan during March 1st to 31st October 2010. All Patients (aged >18 years) were included. Results: Overall 725 patients were included. The performed surgical procedures were 751; of these $578(76.9 \%)$ were Caesarean sections. Overall rate of wound infection was $7.8 \%$. The rate of wound infection among patients operated on for caesarean section and abdominal hysterectomy was $8.3 \%$, and $9.2 \%$, respectively. Multivariate logistic analysis showed that body mass index $[B M I] \geq 30 \mathrm{~kg} / \mathrm{m}^{2}$ OR 2.1, 95\% Cl (1.1 - 4.0), $(P=0.019)$ was the major independent risk factor for occurrence of wound infection. Evaluation of prescriptions' parameters against the stated criteria showed that $113(15.8 \%)$ patients were given antibiotics with adequate spectrum of activity, 611 (85.3\%) given sub-dose/s, $83(11.6 \%)$ received the first preoperative dose/s in a proper time window, and $716(100 \%)$ had prophylaxis for extended duration. Overall conformity to the stated criteria for the evaluation of prescription's parameters was not achieved in all prescriptions. Conclusions: In this setting, antibiotics were irrationally used and wound infection rate was high, and the situation calls for multiple interventions to correct the situation, through the activation of the infection control committee in the hospital and development of antimicrobial subcommittee to develop policies for the use and auditing of prophylactic antibiotics.

\section{KEYWORDS}

Prophylactic Antibiotics; Wound Infection; Obstetrics and Gynecology; Sudan

\section{INTRODUCTION}

Surgical site infection (SSI) remains one of the most important problems in infection control. SSIs increase the length of hospital stay and increase cost of care [1,2]. The obstetric and gynecological procedures at high risk of post operative infection include vaginal and abdominal hysterectomy and Caesarean section [3]. Compared with women delivered vaginally, those delivered by caesarean section at increase risk of infection (2-fold - 20fold) [4]. Infectious morbidity consisting primarily of endometritis and wound infection remain a leading cause of post operative complications [5].

The principals of surgical prophylaxis have been established over years. Selection of antibiotic for prophylaxis should be based on its activity against anticipated bacteria at the specific surgical site [6]. Properly timed accurate dose of preoperative antibiotics reduces the incidence of SSI [7]. Single dose of antimicrobial with a long enough half-life to achieve activity throughout the 
operation is adequate [8]. Prolonged use of prophylactic antimicrobials has been associated with the emergence of resistant bacterial strains [9].

Prophylactic antibiotic reduces the incidence of endometritis, wound infection, post-partum febrile morbidity, and incidence of urinary tract infections following both elective and non-elective Caesarean section [10]. There is evidence that the routine use of prophylactic antibiotics is justified in women undergoing vaginal, abdominal or radical hysterectomy [11].

The main objectives of this study were to quantify the rate of postoperative wound infection, to identify risk factors for its occurrence, and to audit the use of antibiotics prescribed for surgical prophylaxis.

\section{METHODLOGY}

This was a prospective cross-sectional study conducted in the Obstetrics and Gynaecology Department, Khartoum Teaching Hospital, Sudan. All patients, aged > 18 years admitted during March 1st to 31st October 2010 for elective surgery were included. A verbal informed consent from the patient was obtained. Exclusion criteria included: antibiotic use for non-prophylactic purposes 48 hours prior to surgery, a principal diagnosis suggestive of a preoperative infectious disease, a procedure involving the insertion of an implant, a surgical procedure that did not involve incision, patients already recruited in the study that were scheduled for further surgery, patients completed one month follow up, and patients who refused to participate in the study.

Data were collected by trained nurses using a precoded questionnaire that had been developed by the research team; this was tested for applicability among 25 patients. Demographic data were obtained directly from the patients, intra-operative data were collected on an observational basis, and data about postoperatively prescribed antibiotics were extracted from patients' hospital files. The following variables were recorded: sex; age in years; admission, surgery and discharge dates; body mass index; and presence of co-morbidities. The American Society of Anesthesiologists score (ASA score), name of operation, and category of operation, duration of operation in hour, and fixation of surgical drain were also recorded. A section in the questionnaire was designed to collect data on wound infection (occurrence, when detected during admission or after discharge and clinical signs). For the patients who received prophylactic antibiotic/s in the operating room the following parameters were recorded: generic name of antibiotic/s, timing of first preoperative dose in relation to the first incision time, and the first preoperative antibiotic dosage/s. In addition to the duration of prophylaxis, the above mentioned parameters were also registered for patients who were given antibiotics postoperatively.
Wound infection was detected by two methods: Bedside and post-discharge surveillance. Bedside surveillance involved following the patient during hospital admission and started from the day after surgery until the patient was discharged. Post-discharge surveillance was conducted by phoning the patients for up to 4 telephone calls (day 7, 14, 21, 28 of surgery) during a period of one month after discharge. A trained nurse administered to the patient structured questions about the presence of any sign/s of wound infection. Patients who returned to the hospital after reporting any sign/s of wound infection; confirmation of the diagnosis of wound infection was done in collaboration with the unit performed the procedure. For patients who did not return back to the hospital, signs of wound infection were recorded as disclosed by the patient during the interview. Wound infection definition and diagnosis was based on the criteria of the Center of Disease Control (CDC) [12].

Drug utilization reviews were performed by assessing the prescriptions against the guidelines published by the Scottish Intercollegiate Guidelines Network (SIGN) [13]. These guidelines were considered to be the best, compared with others, regarding levels of evidence and strength of recommendations. Each prescription's parameters were assessed against the following criteria:

- Indications for prophylaxis were considered to be "recommended" if the indication was "highly recommended", "recommended", or "should be considered" using the SIGN guidelines, and "not recommended" if it was not.

- Choice of antibiotic with respect to the spectrum of coverage and the bacteria most likely to be encountered at the specific surgical site: "narrow"-did not cover the anticipated range of bacteria; "adequate" covered the anticipated bacteria; "broad" or "unnecessary combination”-covered more bacteria than anticipated [6].

- Time of administration of the first preoperative dose/s: "too early"-if given $>1$ hour before incision was made; "proper"-if given within 30 - 60 min before incision [14]; "late"-if given between 0 and 29 min before the incision; and "too late"-if given after the incision was made.

- Accuracy of the first preoperative dose/s (based on concentration used for surgical prophylaxis purposes in clinical trials for each antibiotic).

- Duration of prophylaxis: “appropriate”-if given as one preoperative dose and "inappropriate"-if extended postoperatively [13].

If more than one drug were prescribed for a single operation, all the parameters for each drug were evaluated separately. The prescription was considered "concordant" if it satisfied the above mentioned criteria for every drug prescribed. Any divergence from the criteria for any of 
the antibiotics, the prescription was considered "discordant”. For patients who developed a wound infection during admission, only antibiotics prescribed prior to the onset of infection were registered; this was done to differentiate between prophylactic and treatment courses.

Percentages and means were used to describe the variables. Analysis aimed to develop a multivariate model to allow prediction of outcome in the presence of potential predictors or covariates (age in year, body mass index $\mathrm{Kg} / \mathrm{m}^{2}$, co-morbidity, diabetes, and ASA score). Crude logistic regression analyses were performed as initial steps of qualifying covariates to be included in multivariate logistic regression analyses. Covariates with p-values $\leq 0.25$ were included to develop an initial reduced model. Multicollinearity among the covariates was assessed using variance inflation factors. Variables that tested insignificant (with p-values $>0.05$ ) were then eliminated from this model and interactions were tested. Each variable was sequentially removed at a time and its significance was tested. Likelihood ratio tests were used to compare models and Hosmer and Leme show test was used to assess goodness of fit of the final model. All statistical tests were conducted by using STATA version 12 .

The study was approved by the National Health Research Ethics Committee, National Ministry of Health, Sudan.

\section{RESULTS}

Overall 1148 patients were scheduled for surgery, of them 964 (83.9\%) were eligible. Patients completed the follow-up period were $725,\{87.6 \%$ were $<40$ years old $(n=635)\}$. Healthy patients were $634(87.4 \%)$, obese patients were 203(28\%), and diabetics were 21(2.9\%). Table 1 shows patients and procedures characteristics.

The performed surgical procedures were 751. Multiple surgical interventions through the same incision was done for 26 (3.9\%) of the patients. Caesarean sections were 578 (76.9\%) and 65 (8.7\%) were abdominal hysterectomies. Table 2 showed the distribution of the performed surgical procedures. The rate of postoperative wound infection in all studied procedures was $7.8 \%$. The rate of wound infection among patients operated on for caesarean section and abdominal hysterectomy was $8.3 \%$, and $9.2 \%$, respectively.

Univariate analysis revealed that four variables were significantly associated with the prevalence of wound infection; namely patient's body mass index $(P=0.0069)$, comorbidity $(P=0.0029)$, presence of diabetes $(P=$ $0.0037)$, and ASA score $(P=0.0078)$. Multivariate logistic analysis showed that body mass index [BMI] $\geq 30$ $\mathrm{kg} / \mathrm{m}^{2}$ OR $2.1,95 \%$ CI $(1.1-4.0)$; $(P=0.019)$ was the major independent risk factor for occurrence of wound infection. Table 3 shows wound infection risk factors.

Surgical antibiotic prophylaxis was given in the operating rooms for 716 (98.8\%) patients. Cefuroxime was
Table 1. Patients' and procedures’ characteristics.

\begin{tabular}{|c|c|c|}
\hline Background characteristics & (n) & Parentage \\
\hline \multicolumn{3}{|l|}{ Age (years) } \\
\hline$<30$ & 273 & 37.7 \\
\hline 30 to $<40$ & 362 & 49.9 \\
\hline 40 to $<50$ & 52 & 7.2 \\
\hline$\geq 50$ & 38 & 5.2 \\
\hline \multicolumn{3}{|l|}{ Body mass index $\left(\mathrm{Kg} / \mathrm{m}^{2}\right)$} \\
\hline$<20$ & 7 & 1.0 \\
\hline 20 to $<25$ & 271 & 37.3 \\
\hline 25 to $<30$ & 244 & 33.7 \\
\hline$\geq 30$ & 203 & 28.0 \\
\hline \multicolumn{3}{|l|}{ Co-morbidity } \\
\hline Yes & 65 & 9.0 \\
\hline No & 660 & 91.0 \\
\hline \multicolumn{3}{|l|}{ Diabetes } \\
\hline Yes & 21 & 2.9 \\
\hline No & 704 & 97.1 \\
\hline \multicolumn{3}{|l|}{ ASA score } \\
\hline 1 & 634 & 87.4 \\
\hline 2 & 90 & 12.5 \\
\hline 3 & 1 & 0.1 \\
\hline \multicolumn{3}{|l|}{ Operator } \\
\hline Surgeon & 209 & 28.8 \\
\hline $\begin{array}{l}\text { Others (registrars, medical } \\
\text { officer \& house officers) }\end{array}$ & 516 & 71.2 \\
\hline \multicolumn{3}{|l|}{ Duration of operation/ hour } \\
\hline$<1$ & 553 & 76.3 \\
\hline$\geq 1$ & 169 & 23.3 \\
\hline Missing & 3 & 0.4 \\
\hline \multicolumn{3}{|l|}{ Surgical drain } \\
\hline Yes & 65 & 8.9 \\
\hline No & 659 & 91.0 \\
\hline Missing & 1 & 0.1 \\
\hline \multicolumn{3}{|l|}{ Pre operative time } \\
\hline 0 - 1 day & 617 & 85.1 \\
\hline$>1$ day & 108 & 14.9 \\
\hline \multicolumn{3}{|l|}{ Post operative time } \\
\hline$\leq 2$ days & 329 & 45.4 \\
\hline 3 days & 242 & 33.4 \\
\hline 4 days & 154 & 21.2 \\
\hline Total & 725 & 100 \\
\hline
\end{tabular}

the prophylactic agent of choice given for 663 (92.6\%) patients; of them 611 (92.2\%) had the drug in a dose of $750 \mathrm{mg}$. Amoxicillin plus clavulanic acid (1.2 g) was given for 28 (3.9\%) of the patients, while ceftriaxone (1 
g) was administered for 13(1.8\%), ampicillin plus cloxacillin (250 mg $+250 \mathrm{mg}$ ) for 2 (0.3\%) and 1 (0.1\%) patient given ceftizoxime ( $1 \mathrm{~g})$. Metronidazole infusion (500 mg) was administered for 617 (86.2\%) patients alone or combined with one of the above mentioned agents. Of the patients who operated on for Caesarean sections 553 (95.7\%) and 23 (35.4\%) for abdominal hysterectomies received the combination of Cefuroxime plus metronidazole. Postoperatively antibiotic for prophylaxis was prescribed for all patients. Table 4 shows prescribing trends of antibiotics in the postoperative period.

Evaluation of prescription parameters against the stated criteria showed that; 113 (15.8\%) were given antibiotics with adequate spectrum of activity, 611 (85.3\%) were given sub-dose/s, 83 (11.6\%) received the first preoperative dose/s in a proper time window and 716 parameters against the predetermined criteria. Overall (100\%) had prophylaxis for extended duration (average 8 days). Table 5 shows the evaluation of prescription's

Table 2. The performed surgical operations.

\begin{tabular}{ccc}
\hline Name of surgical procedure & $\begin{array}{c}\text { Frequency } \\
\text { (n= 751) }\end{array}$ & \% \\
\hline Caesarean section & 578 & $76.9 \%$ \\
Abdominal hysterectomy & 65 & 8.7 \\
Myomectomy & 47 & 6.3 \\
Laparotomy & 28 & 3.7 \\
Tubes legation & 18 & 2.4 \\
Ovarian cystectomy & 13 & 1.7 \\
Others & 2 & 0.3 \\
Total & 751 & $100 \%$ \\
\hline
\end{tabular}

Table 3. Wound infection risk factors.

\begin{tabular}{|c|c|c|c|c|}
\hline \multirow{2}{*}{ Covariates } & \multicolumn{2}{|c|}{ Univariable analysis } & \multicolumn{2}{|c|}{ Multivariable analysis } \\
\hline & Crude OR (95\% CI) & p-value & Adjusted OR (95\% CI) & p-value \\
\hline Age (years) & & 0.626 & & \\
\hline$<30$ & 1.0 & & & \\
\hline 30 to $<40$ & $1.0(0.5-1.7)$ & & & \\
\hline 40 to $<50$ & $0.5(0.1-2.0)$ & & & \\
\hline Body mass index $\left(\mathrm{kg} / \mathrm{m}^{2}\right)$ & & 0.0069 & & \\
\hline$<25$ & 1.0 & & 1.0 & \\
\hline 25 to $<30$ & $0.7(0.4-1.6)$ & & $0.7(0.4-1.6)$ & 0.447 \\
\hline$\geq 30$ & $2.1(1.1-4.0)$ & & $2.1(1.1-4.0)$ & 0.019 \\
\hline Co-morbidity & & 0.0029 & & \\
\hline Yes & 1.0 & & & \\
\hline No & $0.3(0.2-0.6)$ & & & \\
\hline Diabetes & & 0.0037 & & \\
\hline Yes & 1.0 & & & \\
\hline No & $0.2(0.1-0.5)$ & & & \\
\hline ASA score & & 0.0078 & & \\
\hline 1 & 1.0 & & & \\
\hline 2 & $2.6(1.3-4.9)$ & & & \\
\hline Surgical operator & & 0.1911 & & \\
\hline Surgeon & 1.0 & & & \\
\hline Others & $1.5(0.8-3.0)$ & & & \\
\hline Duration of operation in hours & & 0.9717 & & \\
\hline$<1$ & 1.0 & & & \\
\hline$\geq 1$ & $1.0(0.5-1.9)$ & & & \\
\hline No & $0.8(0.3-2.0)$ & & & \\
\hline Pre operative time & & 0.3409 & & \\
\hline 0 - 1 day & 1.0 & & & \\
\hline$>1$ day & $0.7(0.3-1.6)$ & & & \\
\hline Post operative time & & 0.1722 & & \\
\hline$\leq 2$ days & 1.0 & & & \\
\hline 3 days & $1.8(1.0$ - 3.3) & & & \\
\hline
\end{tabular}


Table 4. Antibiotics prescribed postoperatively.

\begin{tabular}{ccc}
\hline Name of antibiotic & Frequency $(\mathbf{n}=\mathbf{7 2 5})$ & (\%) \\
\hline Metronidazole & 718 & 99.0 \\
Cefuroxime & 647 & 89.2 \\
Co-amoxiclav & 369 & 50.9 \\
Cephalexin & 94 & 13.0 \\
Cefpodoxime & 53 & 7.3 \\
Cefriaxone 1 g & 49 & 6.8 \\
Ampicillin + cloxacillin 500 mg & 18 & 2.5 \\
Cefixime & 10 & 1.4 \\
\hline
\end{tabular}

Table 5. Evaluation of prescription's parameters.

\begin{tabular}{|c|c|c|}
\hline & $\begin{array}{l}\text { Parameter } \\
\text { Frequency }\end{array}$ & Percentage \\
\hline \multicolumn{3}{|l|}{ Choice of antibiotic: } \\
\hline Narrow & 44 & 6.1 \\
\hline Adequate & 113 & 15.8 \\
\hline Broad or unnecessary combination & 559 & 78.1 \\
\hline \multicolumn{3}{|l|}{ Dose accuracy: } \\
\hline Accurate & 105 & 14.7 \\
\hline Sub-dose & 611 & 85.3 \\
\hline \multicolumn{3}{|l|}{$\begin{array}{c}\text { Timing of the first preoperative } \\
\text { dose: }\end{array}$} \\
\hline Early & 37 & 5.2 \\
\hline Proper & 83 & 11.6 \\
\hline Late & 421 & 58.8 \\
\hline Too late & 175 & 24.4 \\
\hline \multicolumn{3}{|l|}{ Duration of prophylaxis: } \\
\hline Single dose & 0 & 0 \\
\hline Extended duration & 716 & 100 \\
\hline Total & 716 & 100 \\
\hline
\end{tabular}

conformity to the stated criteria for the evaluation of prescription's parameters was not achieved in all prescriptions analyzed.

\section{DISCUSSION}

Despite the fact that there was an infection control committee at the hospital where the current study was conducted, but there was no established method for wound infection surveillance of inpatients or discharged patients. Telephone call method was selected to detect wound infections following patient discharge from the hospital. The selection of this method was based on the fact that each surgical unit had a different protocol for follow-up visits after discharge; for example, the first follow-up visit for procedures such as caesarean section is typically at 5 weeks after surgery. Thus, it was expected that the telephone call method would provide equal opportunities for follow-up in all patients. Nearly $75 \%$ of the recruited patients completed one month follow-up. In contrast, this percentage of patients was low when compared with the result of a survey conducted in Norway where by only $10 \%$ of the cohort did not complete the follow up period [15].

The results of the present study showed that the rate of postoperative wound infection among patients operated on for Caesarean section was $8.3 \%$. This was the same to the rate of wound infection reported by Kaplan et al. [16] (8.1\%) in a Jordanian hospital. The rate of wound infection after abdominal hysterectomy was $9.2 \%$; this rate was high when compared to the rate of infection of $2.53 \%$ documented in multi-centre surveillance [17].

The results of the current study revealed that presence of diabetes on univariate analysis and body mass $>=30$ $\left(\mathrm{kg} / \mathrm{m}^{2}\right)$ on multivariate logistic analysis were found to be significantly associated with the prevalence of wound infection. In contrast, Schneid-Kofman et al. [18] identified by multivariable logistic regression among other factors associations between obesity and diabetes with early wound infection among Caesarean deliveries. In a prospective multicentre cohort study Wloch C et al. [19] followed the patients for one month and used multivariable analysis, they found that being overweight or obese are the major independent risk factors for infection. This was in agreement with the results of the multivariable logistic regression analysis of the present study.

The results of auditing of prophylactic antibiotic use in the current study showed a great variation in prescribing patterns for the same surgical intervention between different units. Variations in prescribing practices were also reported in an international survey conducted to examine prescribing patterns of antibiotics used for prophylaxis in Caesarean section [20]. The use of broad spectrum and multidrug regimens was common features of the practice in that survey.

Overall; prophylaxis was administered to approximately $99 \%$ of the patients in the operating room, this reflects general awareness with the role of prophylaxis in the prevention of postoperative infection. In contrast, Taylor et al. [21] observed that surgical prophylaxis was omitted in $71.1 \%$ of hysterectomy cases.

The second generation cephalosporin cefuroxime was prescribed for the majority of the patients as preoperative agent. Cefuroxime in general is less active against staphylococci, which is the most causative agents of postoperative infection in elective surgery, than the first generation cephalosporin [22] and with a little activity against $B$. Fragilis [23]. The drug administered in a combination with metronidazole for the majority of Caesarean section cases. However, this combination was 
omitted in the majority of hysterectomy cases where anaerobic bacteria are most frequently encountered.

Proper timing of administration of antibiotics in relation to surgical incision is of utmost importance [6]. Inappropriate timing of the first preoperative dose was an important finding in this study. The majority of patients received this in a time window of 0 - 29 min before surgical incision. The optimization of the initial dose of prophylactic antibiotics is important to establish an inhibitory concentration of the drug in the serum and tissues by the time the skin is incised [6]. In contrast, in another study only $(11.2 \%)$ received antibiotics within I hour before surgical incision, while (41.6\%) received them within 2 hours of surgery [24]. Nearly $85.3 \%$ of the patients recruited in this study were given a sub- preoperative dose (750 mg of cefuroxime), despite the fact that $28.0 \%$ of the patients were obese. Recent published guidelines on antibiotic prophylaxis in gynecologic procedures recommended doubling the antibiotic dose in patients with morbid obesity (BMI > $35 \mathrm{~kg} / \mathrm{m}^{2}$ ) [25].

Generally; the duration of prophylaxis administered for patients recruited in this study was extended beyond the first preoperative dose with an average of eight days regardless the type of surgical intervention. Short-term preoperative antimicrobial prophylaxis in obstetric and gynecological surgery was found to be useful and gives the benefit of minimal toxicity and decrease the risk of antibiotic resistance [26]. Unawareness of healthcare providers with evidence-based guidelines and fear from negative consequences of postoperative infections complications are strong reasons for extending the duration prophylaxis.

The reasons for the high rate of infection documented in this study were attributed to the improper implementation of infection control measures, improper preparation and assessment of patients before operations. The excessive use of broad spectrum antibiotics, administration of antibiotics in sub-dosing, improper timing of first preoperative dose/s of antibiotics may also be responsible factors.

The study had some limitations; some patients may fail to identify minor signs of wound infection during telephone interview. The 30 - 60 min time window before surgical incision was considered adequate for all of the prophylactic agents, despite the difference in pharmacokinetics and pharmacodynamics characteristics of the administered antibiotics.

\section{CONCULSION}

In conclusion, in this setting, antibiotics were irrationally used with respect to all audited parameters and the rate of wound infection was high and called for multiple interventions to improve adherence to infection control measures, giving infection prevention more attention with allocation of resources, and activation of infection control committee and development of antimicrobial subcommittee to develop policies for the use of antibiotics in surgery.

\section{ACKNOWLEDGEMENTS}

The authors would like to thanks Amipharma Laboratories, Pharma Exir Company, and Tabouk Medical Company, Sudan as part of this work was financially supported by them.

\section{REFERENCES}

[1] Kirkland, K.B., Briggs, J.P., Trivette, S.L., Wilkinson, W.E. and Sexton, D.J. (1999) The impact of surgical-site infections in the1990s: Attributable mortality, excess length of hospitalization, and extra costs. Infection Control and Hospital Epidemiology, 20, 725-730.

http://dx.doi.org/10.1086/501572

[2] Merle, V., Germain, J.M., Chamouni, P., Daubert, H., Froment, L., Michot, F., et al. (2000) Assessments of prolonged hospital stay attributable to surgical site infections using appropriateness evaluation protocol. American Journal of Infection Control, 28, 109-115. http://dx.doi.org/10.1067/mic.2000.102353

[3] Guaschino, S., De Santo, D. and De Seta, F. (2002) New perspectives in antibiotic prophylaxis for obstetric and gynecological surgery. Journal of Hospital Infection, 50, S513-S516. http://dx.doi.org/10.1053/jhin.2001.1123

[4] Gibbs, R.S. (1980) Clinical risk factors for puerperal infection. Obstetrics \& Gynecology, 55, 178S-184S. http://dx.doi.org/10.1097/00006250-198003001-00045

[5] Henderson, E. and Love, E.J. (1995) Incidence of hospitalacquired infections associated with caesarean section. Journal of Hospital Infection, 29, 245-255. http://dx.doi.org/10.1016/0195-6701(95)90271-6

[6] Mangram, A.J., Horan, T.C., Pearson, M.L., Silver, L.C. and Jarvis, W.R. (1999) Guideline for prevention of surgical site infection, 1999. Centers for Disease Control and Prevention (CDC) Hospital Infection Control Practices Advisory Committee. American Journal of Infection Control, 27, 97-132. http://dx.doi.org/10.1016/S0196-6553(99)70088-X

[7] Classen, D.C., Evans, R.S., Pestotnik, S.L., Horn, S.D., Menlove, R.L. and Burke, J.P. (1992) The timing of prophylactic administration of antibiotics and the risk of surgical-wound infection. The New England Journal of Medicine, 32, 281-286. http://dx.doi.org/10.1056/NEJM199201303260501

[8] McDonald, M., Grabsch, E., Marshall, C. and Forbes, A. (1998) Single- versus multiple-dose antimicrobial prophylaxis for major surgery: A systematic review. Australian and New Zealand Journal of Surgery, 68, 388-396. http://dx.doi.org/10.1111/j.1445-2197.1998.tb04785.x

[9] Harbarth, S., Samore, H.M., Lichtenberg, D. and Carmeli, Y. (2000) Prolonged antibiotic prophylaxis after cardiovascular surgery and its effect on surgical site infections and antimicrobial resistance. Circulation, 101, 2916-2921. 
http://dx.doi.org/10.1161/01.CIR.101.25.2916

[10] Smaill, F. and Hofmeyr, G.J. (2010) Antibiotic prophylaxis for cesarean section. Cochrane Database of Systematic Reviews, 1, Article ID: CD000933. http://dx.doi.org/10.1002/14651858.CD000933.pub2

[11] Kwarteng, F., Ahluwalia, B. and Osborne, N.G. (2008) Antibiotics prophylaxis in gynecology. Journal of Gynecologic Surgery, 24, 175-179.

[12] Horan, T.C., Gaynes, R.P., Martone, W.J., Jarvis, W.R. and Emori, T.G. (1992) CDC definitions of nosocomial surgical site infections, 1992: A modification of CDC definitions of surgical wound infections. Infection Control and Hospital Epidemiology, 13, 606-609. http://dx.doi.org/10.1086/646436

[13] Scottish Intercollegiate Guidelines Network (2008) Antibiotic prophylaxis in surgery. A national clinical guideline. http://www.sign.ac.uk/pdf/sign104.pdf

[14] American Society of Health—System Pharmacists (ASHP) (2012) ASHP therapeutic guidelines on antimicrobial prophylaxis in surgery. http://www.ashp.org/s_ashp/docs/files/BP07/TG_Surgical .pdf

[15] Eriksen, H.M., Saether, A.R., Løwer, H.L., Vangen, S., Hjetland, R., Lundmark, H., et al. (2009) Infection after cesarean sections. Tidsskrift for Den Norske Legeforening, 129, 618-622. http://dx.doi.org/10.4045/tidsskr.09.24093

[16] Kaplan, N.M., Smadi, A.A., Al-Tanni, M.I. and El-Qudah, M.A. (2003) Microbiology of wound infection after cesarean in a Jordanian hospital. Eastern Mediterranean Health Journal, 9, 1068-1074.

[17] National Nosocomial Infections Surveillance System (2004) National nosocomial Infections surveillance (NNIS) system report, data summary from January 1992 through June 2004. American Journal of Infection Control, 32, 470-485. http://dx.doi.org/10.1016/j.ajic.2004.10.001

[18] Schneid-Kofman, N., Sheiner, E., Levy, A. and Holcberg, G. (2005) Risk factors for wound infection following ce- sarean deliveries. International Journal of Gynecology \& Obstetrics, 90, 10-15. http://dx.doi.org/10.1016/j.ijgo.2005.03.020

[19] Wloch, C., Wilson, J., Lamagni, T., Harrington, P., Charlett, A. and Sheridan, E. (2012) Risk factors for surgical site infection following caesarean section in England: Results from a multicentre cohort study. BJOG, 119, 1324-1333. http://dx.doi.org/10.1111/j.1471-0528.2012.03452.x

[20] Huskins, W.C., Ba-Thike, K., Festin, M.R., Limpongsanurak, S., Lumbiganon, P., Peedicayil, A., et al. (2001) An international survey of practice variation in the use of antibiotic prophylaxis in cesarean section. International Journal of Gynecology \& Obstetrics, 73, 141-145. http://dx.doi.org/10.1016/S0020-7292(01)00365-4

[21] Taylor, G., Herrick, T. and Mah, M. (1998) Wound infections after hysterectomy: Opportunities for practice improvement. American Journal of Infection Control, 26, 254-257. http://dx.doi.org/10.1016/S0196-6553(98)80009-6

[22] Kalman, D. and Barriere, S.L. (1990) Review of the pharmacology, pharmacokinetics and clinical use of cephalosporin. Texas Heart Institute Journal, 17, 203-215.

[23] Treatment guidelines from the medical letter. (2009) Antimicrobial Prophylaxis for Surgery, 7, 47-51.

[24] Choi, W.S., Song, J.Y., Hwang, J.H., Kim, N.S., Cheong, H.J., et al. (2007) Appropriateness of antibiotic prophylaxis for major surgery in Korea. Infection Control and Hospital Epidemiology, 28, 997-1002. http://dx.doi.org/10.1086/519180

[25] Van Eyk, N. and Van Schalkwyk, J. for Infectious Diseases Committee (2012) Antibiotic prophylaxis ingynaecologic procedures. Journal of Obstetrics and Gynaecology Canada, 34, 382-391.

[26] Giuliani, B., Periti, E. and Mecacci, F. (1999) Antimicrobial prophylaxis in obstetric and gynecological surgery. Journal of Chemotherapy, 11, 577-580. 